Original article

\title{
Accumulation and biodistribution of gold nanoparticles in the mesenteric lymph nodes at oral administration
}

\author{
Olga V. Zlobina ${ }^{1}$, Svetlana S. Pakhomiy ${ }^{1}$, Alla B. Bucharskaya ${ }^{1}$, Irina O. Bugaeva ${ }^{1}$, Galina N. Maslyakova ${ }^{1}$, \\ Nikolai G. Khlebtsov ${ }^{2}$, Boris N. Khlebtsov ${ }^{2}$, Vladimir A. Bogatyrev ${ }^{2}$ \\ ${ }^{1}$ Saratov State Medical University n.a. V.I. Razumovsky, Saratov, Russia \\ ${ }^{2}$ Institute of Biochemistry and Physiology of Plants and Microorganisms of Russian Academy of Sciences, Saratov, Russia
}

Received 20 May 2013, Accepted 15 July 2013

(C) 2013, Zlobina O.V., Pakhomiy S.S., Bucharskaya A.B., Bugaeva I.O., Maslyakova G.N., Khlebtsov N.G., Khlebtsov B.N., Bogatyrev V.A. (C) 2013, Russian Open Medical Journal

Abstract: The aim: to conduct analysis of the accumulation and biodistribution of gold nanoparticles in the structural and functional areas of mesenteric lymph nodes of white rats conducted with regard to the size and duration of the oral administration. The methods of dark field microscopy with Leica DM 2500 microscope were used to assess biodistribution of gold nanoparticle. The histochemical reaction of silver amplification with silver lactate by Danscher was used to confirm its identification. Results: It was found that the gold nanoparticles of 1-3 nm were not detected by these methods in any of the areas of the lymph nodes regardless of the duration of administration, gold nanoparticles of sizes 15 and $50 \mathrm{~nm}$ were detected in the form of clusters in the cytoplasm of macrophages and lymphocytes mainly in the mantle zone of lymphoid follicles and brain strands. Conclusion: It was established that the gold nanoparticles of sizes 15 and $50 \mathrm{~nm}$ were detected in the form of clusters in the cytoplasm of macrophages and lymphocytes

Keywords: gold nanoparticles, mesenterial lymphatic nodes, biodistribution, dark field microscopy

Cite as Zlobina OV, Pakhomiy SS, Bucharskaya AB, Bugaeva IO, Maslyakova GN, Khlebtsov NG, Khlebtsov BN, Bogatyrev VA. Accumulation and biodistribution of gold nanoparticles in the mesenteric lymph nodes at oral administration. Russian Open Medical Journal $2013 ; 2$ : 0301.

Correspondence to Prof. Galina N. Maslyakova. Address: Saratov State Medical University, 121, Bolshaya Kazachya str., Saratov, 410012, Russia. E-mail: gmaslyakova@yandex.ru

\section{Introduction}

The use of nanomaterials in medicine attracts more and more attention of different specialties physicians. It is assumed that their use will lead to the revolutionary advances in the treatment of many diseases through their ability to interact with biological tissues at the molecular and cellular levels [1-3].

In recent years colloidal gold was widely used in oncology, biochemistry, immunology and in the treatment of several autoimmune diseases [4, 5]. However, despite wide application of gold nanoparticles, many aspects of safe use require detailed analysis. In particular, the analysis of relations between the possible toxicity, size duration and route of administration of gold nanoparticles is sufficiently studied.

The studies of subtle morphofunctional changes in immune system organs, in particular in the lymph nodes are important in this respect [6, 7]. An analysis of the accumulation and biodistribution of gold nanoparticles (GN) in the mesenteric lymph nodes plays an essential role in the evaluation of immunotoxicity of experimentally test substance which may be indirect evidence of the sequence deployment of the immunological response to oral administration of GN.

The purpose of study is to conduct analysis of biodistribution and accumulation of gold nanoparticles in the structural and functional zones of lymph nodes with regard to size of nanoparticles and duration of oral administration.

\section{Materials and methods}

The study was performed on 120 healthy mature albino male rats weight 180-220 g accordingly "Guidelines for the experimental (preclinical) studies of new pharmacological agents" [8]. The study included three series of experiments, in which the animals of experimental groups were administered orally by gold nanoparticles size 1-3 nm, $15 \mathrm{~nm}$ and $50 \mathrm{~nm}$ for 8, 16 and 30 days. Biopsy specimens were performed after 24 hours of the last administration. Gold nanoparticles size $1-3 \mathrm{~nm}, 15 \mathrm{~nm}$ and $50 \mathrm{~nm}$ synthesized in the laboratory Nanobiotechnologies IBPPM RAS (Saratov) were used in the experiment (gold concentration in all samples - $57 \mathrm{ug} / \mathrm{ml}$ ). To increase biocompatibility and bioavailability, nanoparticles were conjugated with polyethylene glycol PEG-SH (Nektar, USA).

Serial sections of lymph nodes with 5-7 microns in thickness were stained by hematoxylin-eosin. To assess the biodistribution of $\mathrm{GN}$ in various areas of mesenteric lymph nodes, dark field microscopy method was applied by using a microscope Leica DM 2500 with color CCD camera and the special attachment that allows to carry out lateral illumination at $1000 \times$ magnification. Dark-field illumination mode was implemented on devices LEICA DM LEICA LMD 2500 and 7000. Lighter LEICA CLS 150 with two optical fibers was used as a source of side lighting (BO) using, fiber tips were set positioning at a distance of about 2 inches on either 
side of the lens as close as possible to the object plane. To confirm the identification of GN histochemical reaction of amplification by Danscher silver with silver lactate was used, in which in the case of positive reactions under illumination of "light field transmitted light" gold nanoparticles appear as a large black clusters (aurosomy), in the "dark field" the aurosomes look like brightly glowing objects with red tint on a dark background. A special computer program for analysis of microscopic images of Image J was used to quantify the distribution of aurosomes in different areas of the lymph nodes.

The program package "STATISTICA 6.0" (Stat Soft Inc, USA) was used for the statistical analysis of the study results. The verification of the distribution normality of the sample values was performed by using the Kolmogorov-Smirnov test. We calculated the arithmetic mean (M), the average error of the arithmetic mean $(\mathrm{m})$; standard deviation (SD). The significance of differences (P) was determined by using Student's t test.

\section{Results}

Studies have shown that at 8,16 and 30 day oral administration of GN size of 1-3 $\mathrm{nm}$ the aurosomes were not registered in any of the zones of lymph nodes. It can be assumed that the lack of method sensitivity for the determination of the gold particle sizes is indicated. In the group of animals treated with GN size of $15 \mathrm{~nm}$ and $50 \mathrm{~nm}$ the aurosomes were detected in all areas of lymph nodes, and the greatest number of them was mentioned in the cerebral region strands.

The results of quantitative analysis of aurosomes at administration of GN with different sizes and duration of their administration are shown in Table 1.

As follows from the table, GN size of 1-3 nm is not visualized in any of the zones of the lymph nodes. At the same time, regardless of the size of the largest number of GN aurosomes was observed in the area of the brain strands. At 8-day administration of gold nanoparticles size of $15 \mathrm{~nm} 486 \pm 12$ aurosomes in the area of lymph follicles are registered, $21 \pm 3$ aurosomes were registered in paracortical area and $768 \pm 21$ aurosom were registered in the area of the brain strands $(P<0.05)$. At 8-day administration of $50 \mathrm{~nm}$ GN $481 \pm 16$ aurosomes were observed in the area of brain strands (Figure 1), $357 \pm 14$ aurosomes were registered in lymph follicle $(P<0.05)$. It should be noted that the number of aurosomes in all zones of lymph nodes was significantly greater at using nanoparticles with size of $15 \mathrm{~nm}$ than $50 \mathrm{~nm}$ GN in comparable duration of administration $(\mathrm{P}<0.05)$. It can be assumed that the lowest amount of GN size $50 \mathrm{~nm}$ in the lymph nodes was caused by their large size, hindering absorption in the gastrointestinal tract. This thesis is confirmed by studies of P. Jani et al. [9], in which the size-dependent effect of suction polystyrene particles (from $50 \mathrm{~nm}$ to $3000 \mathrm{~nm}$ ) was detected. It is interesting to note the fact that at the sizes of $15 \mathrm{~nm} \mathrm{GN}$ the number of aurosomes in all zones of the lymph nodes increases almost proportionally to the duration of their administration, while AT administration of GN size of $50 \mathrm{~nm}$ this growth is not observed. At increasing duration of administration from 8 to 30 days the amount of aurosomes was increased by $38.1 \%$ at of $15 \mathrm{~nm}$ administrations and by $4.8 \%$ at GN size $50 \mathrm{~nm}$ administrations. These differences are also may be explanated by insufficient suction of $50 \mathrm{~nm}$ nanoparticles in the gastrointestinal tract.

A more detailed analysis of the results allowed us to identify large number of phagocytic macrophages filled with gold nanoparticles in the cells of subcapsular sinus. At its research using dark-field microscopy with side lighting a large number of aurosomes was detected in macrophages that confirm the presence of GN (Figure 2). It can be assumed that the enhanced phagocytosis by macrophages is trigger the immune response at administration of GN.

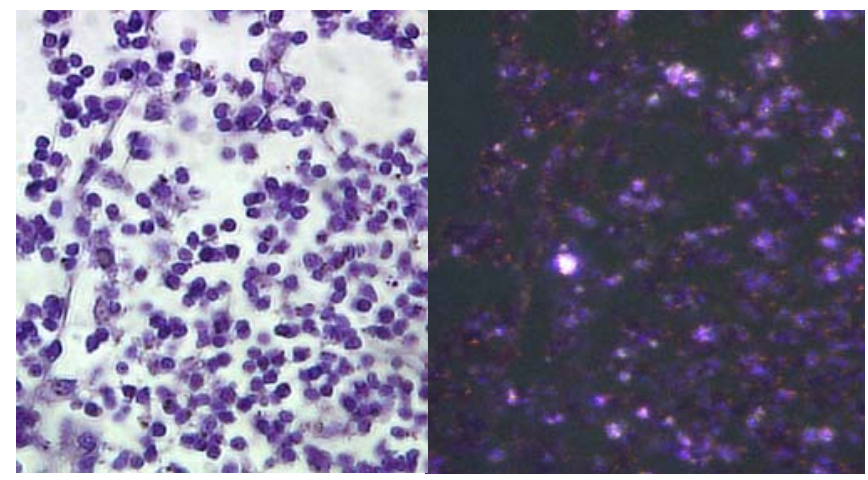

Fig. 1(a,b). Area of brain strands of mesenteric lymph nodes at 30-day administration of $50 \mathrm{~nm}$ GN. x1000. Hematoxylin-eosin (a). Dark-field microscopy (b).

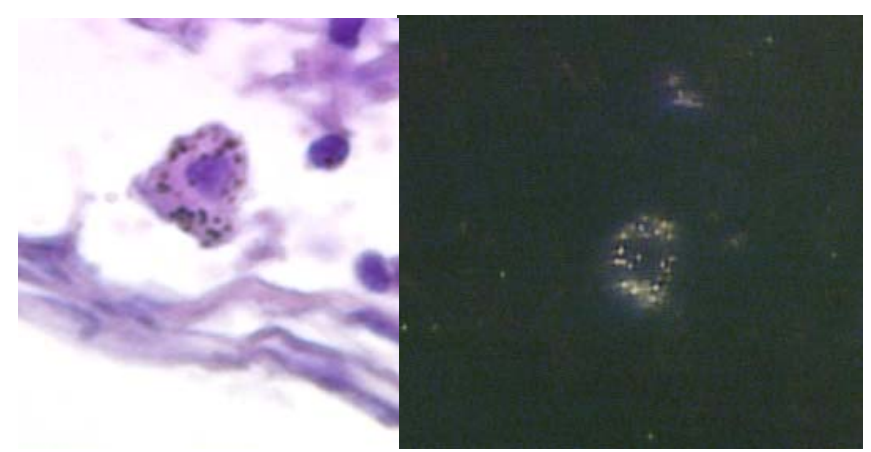

Fig. 2(a,b). Macrophage in the subcapsular area of mesenteric lymph nodes at 16 day administration of $50 \mathrm{~nm} \mathrm{GN}$. Incr.x1500. Hematoxylineosin (a). Dark-field microscopy (b).

Table 1. The distribution of gold nanoparticles in areas of lymph nodes

\begin{tabular}{|c|c|c|c|c|c|c|c|c|c|}
\hline \multirow{3}{*}{ Zone of lymph nodes } & \multicolumn{9}{|c|}{ The number of aurosomes } \\
\hline & \multicolumn{3}{|c|}{$\begin{array}{l}\text { Duration of } \\
\text { administration of } \mathrm{GN} \\
\text { size } 1-3 \mathrm{~nm} \text { (days) }\end{array}$} & \multicolumn{3}{|c|}{$\begin{array}{l}\text { Duration of administration of GN size } 15 \mathrm{~nm} \\
\text { (days) }\end{array}$} & \multicolumn{3}{|c|}{$\begin{array}{l}\text { Duration of administration of GN } 50 \mathrm{~nm} \\
\text { (days) }\end{array}$} \\
\hline & 8 & 16 & 30 & 8 & 16 & 30 & 8 & 16 & 30 \\
\hline Lymph follicles & - & - & - & $486 \pm 12$ & $586 \pm 18$ & $711 \pm 21$ & $357 \pm 14$ & $320 \pm 11$ & $327 \pm 16$ \\
\hline Paracortical area & - & - & - & $21 \pm 3$ & $28 \pm 7$ & $39 \pm 4$ & - & $4 \pm 1,2$ & $6 \pm 2,0$ \\
\hline Area of brain strands & - & - & - & $768 \pm 21$ & $956 \pm 30$ & $1134 \pm 37$ & $481 \pm 16$ & $520 \pm 14$ & $492 \pm 11$ \\
\hline
\end{tabular}




\section{Discussion}

In the latest published data the information of the accumulation and biodistribution of GN in mesenteric lymph nodes are absent [10]. Analysis of the accumulation and distribution of $\mathrm{GN}$ in different areas of lymph nodes may be an indirect evidence of the sequence of the deployment of the immunological response. The study founds that GN size 15 and $50 \mathrm{~nm}$ are registered in all functional areas of the mesenteric lymph nodes with a maximum accumulation in the cerebral sinuses at different times of administration (8, 16 and 30 days). At the same time $\mathrm{GN}$ size of 1-3 nm are not visualized in any of the zones of lymph nodes, which is possible due to the low sensitivity of the method of the study.

\section{Conclusion}

Biodistribution analysis of gold nanoparticles in the structural areas of lymph nodes in experimental animals shows that gold nanoparticles size 1-3 $\mathrm{nm}$ were not registered by darkfield microscopy and autometallography methods. GN size from 15 to $50 \mathrm{~nm}$ was detected as conglomerates in cytoplasm of macrophages and lymphocytes predominantly in the mantle zone of the lymphoid follicles, and brain strands. The extracellular accumulation of GN was founded in brain sinuses.

Conflict of interest: none declared.

\section{Reference}

1. Terekhov Al. Evaluating the performance of Russia in the research in nanotechnology. Journal of Nanoparticle Research 2012; 14: 12501267. (doi: 10.1007/s11051-012-1250-5)

2. Oborotova NA. Pharmaceutical aspects of nanostructured formulations of anticancer drugs. Russian biotherapeutic journal 2009; (1): 8-9. [Article in Russian]

3. Hoet PH, Nemery B. Stimulation of phagocytosis by ultrafine particles. Toxicol Appl Pharmacol 2001; 176: 203. (PMID: 11714254) (doi: 10.1006/taap.2001.9264)

4. Dykman LA, Bogatirev VA, Schogolev WYu, Khlebtsov NG. Gold nanoparticles: synthesis, properties and biomedical applications. Nauka Publ., Moscow, Russia, 2008. [Text in Russian]

5. Blundell G, Henderson WJ, Price EW. Soil particles in the tissues of the foot in endemic elephantiasis of the lower legs. Ann Trop Med Parasitol 1989; 83: 381-385. (PMID: 2604475)

6. Khaitov RM. Fiziologiya immunnoy sistemy [Physiology of immune system]. VINITI, Moscow, Russia, 2001. [Text in Russian]

7. Boland S, Baeza-Squiban A, Fournier T, Houcine O, Gendron MC, Chevrier $\mathrm{M}$, et al. Diesel exhaust particles are taken up by human airway epithelial cells in vitro and alter cytokine production. Am J Physiol 1999; 276: L604-L613. (PMID: 10198358)

8. Guidelines for experimental (preclinical) studies of new pharmacological agents. P.U. Khabriev eds. Meditsina Publ., Moscow, Russia, 2005. [Text in Russian]

9. Jani P, Halbert GW, Langridge J, Florence AT. Nanoparticle uptake by the rat gastrointestinal mucosa: quantitation and particle size dependency. J Pharm Pharmacol 1990; 42: 821-826. (doi: 10.1111/j.2042-7158.1990.tb07033.x) (PMID: 1983142)

10. De Jong WH, Hagens WI, Krystek P, Burger MC, Sips AJ, Geertsma RE. Particle size-dependent organ distribution of gold nanoparticles after intravenous administration. Biomaterials 2008; 29(12): 1912-1919. (doi: 10.1016/j.biomaterials.2007.12.037) (PMID: 18242692)

\section{Authors:}

Olga V. Zlobina - PhD, Assistant, Department of Histology, Saratov State Medical University n.a. V.I. Razumovsky, Saratov, Russia;

Svetlana S. Pakhomiy - MD, Assistant, Department of Pathology Anatomy, Saratov State Medical University n.a. V.I. Razumovsky, Saratov, Russia;

Alla B. Bucharskaya - PhD, Head of Department, Scientific-Educational Centre of Fundamental Medicine and Nanotechnologies, Scientific Research Institute of Fundamental and Clinical Uronephrology, Saratov State Medical University n.a. V.I. Razumovsky, Saratov, Russia;

Irina O. Bugaeva - MD, D.Sc., Professor, Head of Department of Histology, Saratov State Medical University n.a. V.I. Razumovsky, Saratov, Russia;

Galina N. Maslyakova - MD, D.Sc., Professor, Head of Department of Pathology Anatomy, Saratov State Medical University n.a. V.I. Razumovsky, Saratov, Russia;

Nikolai G. Khlebtsov - D.Sc., Professor, Head of Laboratory of Nanobiotechnology, Institute of Biochemistry and Physiology of Plants and Microorganisms of Russian Academy of Sciences, Saratov, Russia;

Boris N. Khlebtsov - D.Sc., Senior Researcher, Laboratory of Nanobiotechnology, Institute of Biochemistry and Physiology of Plants and Microorganisms of Russian Academy of Sciences, Saratov, Russia;

Vladimir A. Bogatyrev - D.Sc., Leading researcher, Laboratory of Nanobiotechnology, Institute of Biochemistry and Physiology of Plants and Microorganisms of Russian Academy of Sciences, Saratov, Russia. 